\title{
Cerebral venous sinus thrombosis 2 weeks after the first dose of mRNA SARS-CoV-2 vaccine
}

\author{
Zaitun Zakaria $^{1,2,3} \cdot$ Nur Asma Sapiai ${ }^{2,3,4} \cdot$ Abdul Rahman Izaini Ghani ${ }^{1,2,3} \mathbb{C}$ \\ Received: 13 April 2021 / Accepted: 20 April 2021 / Published online: 8 June 2021 \\ (c) The Author(s), under exclusive licence to Springer-Verlag GmbH Austria, part of Springer Nature 2021
}

\begin{abstract}
The severe acute respiratory syndrome coronavirus 2 (SARS-CoV-2), also known as coronavirus disease 2019 (COVID-19) is a highly transmissible virus and has become pandemic. Part of the prevention of disease spread by the Malaysian government is by getting COVID-19 vaccine. Using the mRNA technology, the Pfizer/BioNTech vaccine is one of the vaccines been approved by the Drug Control Authority in Malaysia. Herein, we report an immediate complication of cerebral VST after the first dose of the Pfizer/BioNTech vaccine.
\end{abstract}

Keywords Acute respiratory syndrome coronavirus 2 . Coronavirus disease 2019 · Cerebral venous sinus thrombosis

\section{Introduction}

The world has had its eyes opened by the severe acute respiratory syndrome coronavirus 2 (SARS-CoV-2) that started in December 2019 in Wuhan, Hubei, China. The World Health Organization (WHO) aptly changed the name to coronavirus disease 2019 (COVID-19), and since then, the infection has become a pandemic. In Malaysia, extensive measures have been taken to prevent the spread of COVID-19; however, we are dealing with a precarious situation due to the weakening economic growth [16]. The emergence of a promising anti-COVID-19 vaccine gives a platform of hope that the

This article is part of the Topical Collection on Vascular Neurosurgery

Abdul Rahman Izaini Ghani

yoppghani@gmail.com

1 Department of Neurosciences, School of Medical Sciences, Universiti Sains Malaysia, Kubang Kerian, 16150 Kota Bharu, Kelantan, Malaysia

2 Hospital Universiti Sains Malaysia, Universiti Sains Malaysia, Health Campus, Jalan Raja Perempuan Zainab 2, 16150 Kota Bharu, Kelantan, Malaysia

3 Brain and Behaviour Cluster, School of Medical Sciences, Universiti Sains Malaysia, Health Campus, Kubang Kerian, 16150 Kota Bharu, Kelantan, Malaysia

4 Department of Radiology, School of Medical Sciences, Universiti Sains Malaysia, 16150 Kota Bharu, Kelantan, Malaysia virus will soon abate [15]. The national vaccination program started on February 24, 2021 by the Drug Control Authority has approved three vaccines: COVID-19 vaccine AstraZeneca, CoronaVac suspension for injection (Sinovac), and Comirnaty concentrate for injection dispersion (Pfizer/ BioNTech).

The rapid development of vaccines comes with a setback as studies on long-term effects are still unproven. An emerging thromboembolic complication has been reported in hospitalized patients with COVID-19, with a rate of $21-32 \%$ [5, $9,10]$. The hypercoagulable state in those patients causes not only venous thromboembolism (VTE) [5, 7], but also cerebral venous sinus thrombosis (VST) [2], which can be fatal [4]. However, the risk of developing cerebral VST after receiving vaccination has never been reported, particularly in terms of the mRNA COVID-19 vaccine. Here, we report an immediate complication of cerebral VST after the first dose of the Pfizer/BioNTech vaccine.

\section{Case report}

The case involves a 49-year-old Malay male who works as a medical health officer with a history of childhood asthma, allergy to seafood and nonsteroidal medication, and single-vessel coronary artery disease treated by percutaneous transluminal coronary angioplasty 3 years prior. He was on dual antiplatelet therapy for a year, followed by 6 months of single antiplatelet drug therapy; subsequently, 
he became non-compliant. Other than that, he is a nonsmoker, enjoys running ( $\sim \mathrm{km} /$ day $)$, and has a healthy body mass index of 22 . The patient received the first dose of subcutaneous mRNA COVID-19 vaccine (EP2163, Pfizer/BioNTech) on March 1, 2021 and reported mild symptoms of soreness at the injection site and myalgia that lasted for $24 \mathrm{~h}$. Sixteen days later (March 17), the patient complained of a new-onset of mild to moderate headache and giddiness, which initially was thought from the exertion of working. The symptom persisted, requiring a hospital visit 5 days later (March 21). The systemic and neurological examinations were unremarkable, while routine laboratory tests for full blood count, coagulation profile, C-reactive protein, and hepatic and renal function tests were normal. Notably, the platelet was $302 \times 10^{9} / \mathrm{L}$, international normalized ratio of 0.98 (0.86-1.14), prothrombin time of $13 \mathrm{~s}$ (12.6-15.7), activated partial throm-

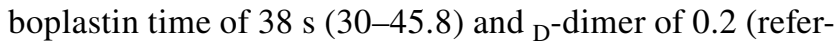
ence value, $<0.5$ ).
A noncontrast computed tomography (CT) of the brain showed cordlike hyperattenuation within the left transverse and sigmoid sinus suggestive of cord or dense clot sign (Fig. 1a,b). The patient elected to ignore the radiological finding and persevere with the symptoms. On March 22, he received the second dose of the vaccine (EP9605, Pfizer/ BioNTech). Due to unresolved and somewhat worsening symptoms, the patient agreed to CT cerebral venography 2 days later. The finding confirmed a long segment-filling defect and empty delta sign within the superior sagittal sinus (SSS), extending into the torcula Herophili, left transverse sinus, and sigmoid sinus to proximal internal jugular vein (Fig. 1c,d). He was immediately started on therapeutic subcutaneous Clexane (1 $\mathrm{mg} / \mathrm{kg}$ twice daily) and antiplatelet therapy (clopidogrel $75 \mathrm{mg}$ ). The autoimmune test and thrombophilia screening returned normal. The symptoms had gradually improved. Repeated CT cerebral venogram 2 weeks post-treatment shows residual cerebral VST (Fig. 1e). Filling defects within the proximal

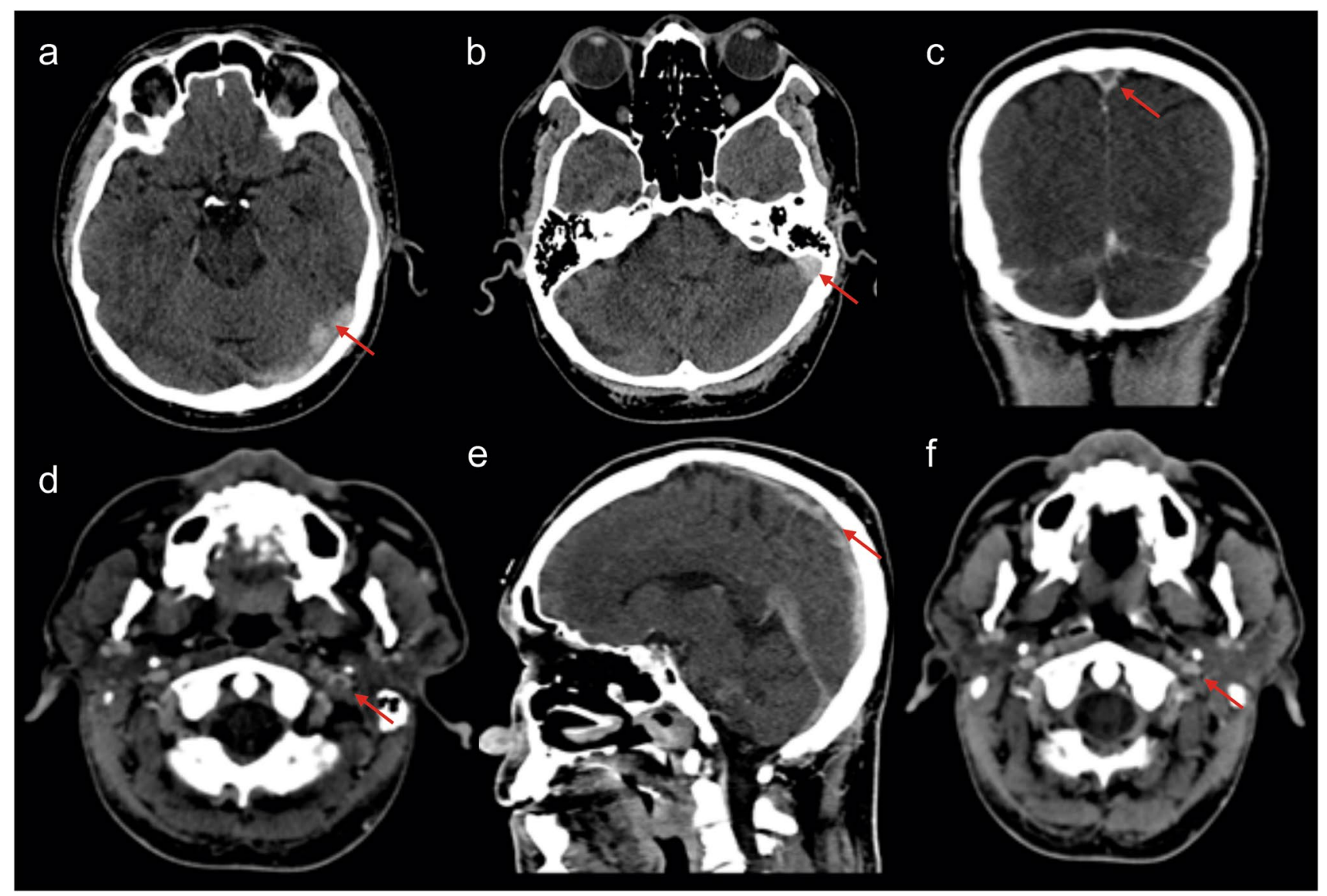

Fig. 1 Radiological finding. a, b The axial view of noncontrast CT scan brain shows hyperattenuation within the left transverse sinus and sigmoid sinus suggestive of cord sign (arrow). $\mathbf{c}$ The coronal view of CT cerebral venogram shows an empty delta sign with $\mathbf{d}$ axial view depicting a central filling defect in the proximal left internal jugular vein. Repeated CT venogram 2 weeks post-treatment in e sagittal and f axial view show residual dura venous thrombosis. There is presence of filling defect within proximal part superior sagittal sinus and well opacified left internal jugular vein 
section of the superior sagittal sinus, left transverse sinus, and left sigmoid sinus were present (Fig. 1f). Opacification were visualized at the distal part of the superior sagittal sinus, torcula Herophili, and left internal jugular vein. Throughout these imaging techniques, no cerebral infarct or edema was seen. Following that, the clexane was switched to apixaban (5 mg twice daily).

\section{Discussion}

The pathophysiology of thrombotic and hypercoagulable states is not fully elucidated. In patients with COVID-19 infection, the commonly associated event is the activation of inflammatory cells with induction of neutrophil extracellular traps (NETs), natural downregulation of anticoagulation during impaired systemic microcirculatory function as a response to endotheliitis, and alveolar capillary microthrombi from local COVID-19-induced immunothrombosis [11]. The presence of the heparin sulfate cell surface receptor acted as a site assisting viral infection [8], giving a possible syndrome similar to autoimmune heparin-induced thrombocytopenia [6, 14]. Perhaps, the patient's allergic history, the immunological response to the mRNA vaccine, as well as the dysregulation of the surface receptor may have triggered or activated thrombosis formation. The risk of cerebral VST is also notable in COVID-19 patients, who commonly present with neurological symptoms and deficits $[1,13]$. The mainstay of treatment is similar to VTE. The risk of thromboembolism and cerebral VST after receiving the Oxford-AstraZeneca vaccine is widely known [12]. Recently, deep vein thrombosis has been reported in a 66-year-old woman following the second dose of the mRNA Pfizer/BioNTech vaccine [3]. Similar to our patient, the reported patient did not have an abnormal coagulation profile, thrombocytopenia,

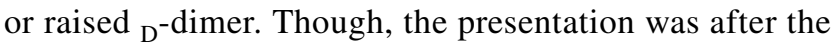
second dose while our patient was at day 16 (after the first dose). There are recently published cases of thrombotic thrombocytopenia and cerebral VST occurring in 9 patients after receiving the adenovirus-based vaccine (AstraZeneca) [6]. The typical symptoms of headache and fever started from days 3 to 16 . Of those cases, fatality was reported in 5 patients. In Norway, there were another 5 cases of cerebral VST been identified after the first dose of a similar vaccine. The laboratory findings and clinical symptoms were much the same, and 3 of the patients had a fatal outcome [14]. Although a single case does not prove an association, our report of a cerebral VST in a male without risk factors after receipt of the first dose of the mRNA based vaccine causes concern.

\section{Declarations}

Informed Consent Consent was obtained for all procedures, including submission to the journal.

Conflict of interest The authors declare that they have no conflict of interest.

\section{References}

1. Abdalkader M, Shaikh SP, Siegler JE, Cervantes-Arslanian AM, Tiu C, Radu RA, Tiu VE, Jillella DV, Mansour OY, Vera V, Chamorro Á, Blasco J, López A, Farooqui M, Thau L, Smith A, Gutierrez SO, Nguyen TN, Jovin TG (2021) Cerebral venous sinus thrombosis in COVID-19 patients: a multicenter study and review of literature. J Stroke Cerebrovasc Dis 30(6):105733

2. Abouhashem S, Eldawoody H, Taha MM (2021) Cerebral venous sinus thrombosis in patients with COVID-19 infection. Interdiscip Neurosurg 24:101091

3. Carli G, Nichele I, Ruggeri M, Barra S, Tosetto A (2021) Deep vein thrombosis (DVT) occurring shortly after the second dose of mRNA SARS-CoV-2 vaccine. Intern Emerg Med 16(3):803-804

4. Cavalcanti DD, Raz E, Shapiro M, Dehkharghani S, Yaghi S, Lillemoe K, Nossek E, Torres J, Jain R, Riina HA, Radmanesh A, Nelson PK (2020) Cerebral venous thrombosis associated with COVID-19. AJNR Am J Neuroradiol 41(8):1370-1376

5. Cui S, Chen S, Li X, Liu S, Wang F (2020) Prevalence of venous thromboembolism in patients with severe novel coronavirus pneumonia. J Thromb Haemost 18(6):1421-1424

6. Greinacher A, Thiele T, Warkentin TE, Weisser K, Kyrle PA, Eichinger S (2021) Thrombotic thrombocytopenia after ChAdOx1 nCov-19 vaccination. N Engl J Med. https://doi.org/10.1056/ NEJMoa2104840

7. Kollias A, Kyriakoulis KG, Dimakakos E, Poulakou G, Stergiou GS, Syrigos K (2020) Thromboembolic risk and anticoagulant therapy in COVID-19 patients: emerging evidence and call for action. Br J Haematol 189(5):846-847

8. Liu J, Thorp SC (2002) Cell surface heparan sulfate and its roles in assisting viral infections. Med Res Rev 22(1):1-25

9. Lodigiani C, Iapichino G, Carenzo L, Cecconi M, Ferrazzi P, Sebastian T, Kucher N, Studt JD, Sacco C, Bertuzzi A, Sandri MT, Barco S (2020) Venous and arterial thromboembolic complications in COVID-19 patients admitted to an academic hospital in Milan, Italy. Thromb Res 191:9-14

10. Longchamp A, Longchamp J, Manzocchi-Besson S, Whiting L, Haller C, Jeanneret S, Godio M, Garcia Martinez JJ, Bonjour T, Caillat M, Maitre G, Thaler JM, Pantet R, Donner V, Dumoulin A, Emonet S, Greub G, Friolet R, Robert-Ebadi H, Righini M, Sanchez B, Delaloye J (2020) Venous thromboembolism in critically ill patients with COVID-19: results of a screening study for deep vein thrombosis. Res Pract Thromb Haemost 4(5):842-847

11. Obi AT, Tignanelli CJ, Jacobs BN, Arya S, Park PK, Wakefield TW, Henke PK, Napolitano LM (2019) Empirical systemic anticoagulation is associated with decreased venous thromboembolism in critically ill influenza A H1N1 acute respiratory distress syndrome patients. J Vasc Surg Venous Lymphat Disord 7(3):317-324

12. Østergaard SD, Schmidt M, Horváth-Puhó E, Thomsen RW, Sørensen HT (2021) Thromboembolism and the Oxford-Astrazeneca COVID-19 vaccine: side-effect or coincidence? Lancet 397(10283): 1441-1443

13. Ostovan VR, Foroughi R, Rostami M, Almasi-Dooghaee M, Esmaili M, Bidaki AA, Behzadi Z, Farzadfard F, Marbooti H, 
Rahimi-Jaberi A, Poursadeghfard M, Fadakar N, Bayat M, Owjfard M, Salehi MS, Zafarmand SS, Mardi F, Safari A, Shahjouei S, Mowla A, Azarpazhooh MR, Zand R, Hooshmandi E, BorhaniHaghighi A (2021) Cerebral venous sinus thrombosis associated with COVID-19: a case series and literature review. J Neurol. https://doi.org/10.1007/s00415-021-10450-8

14. Schultz NH, Sørvoll IH, Michelsen AE, Munthe LA, LundJohansen F, Ahlen MT, Wiedmann M, Aamodt AH, Skattør TH, Tjønnfjord GE, Holme PA (2021) Thrombosis and thrombocytopenia after chadox 1 nCov-19 vaccination. N Engl J Med. https://doi.org/10.1056/NEJMoa2104882

15. Strizova Z, Smetanova J, Bartunkova J, Milota T (2021) Principles and challenges in anti-COVID-19 vaccine development. Int Arch Allergy Immunol 182(4):339-349
16. Umair S, Waqas U, Faheem M (2021) COVID-19 pandemic: stringent measures of Malaysia and implications for other countries. Postgrad Med J 97(1144):130-132

Publisher's note Springer Nature remains neutral with regard to jurisdictional claims in published maps and institutional affiliations. 